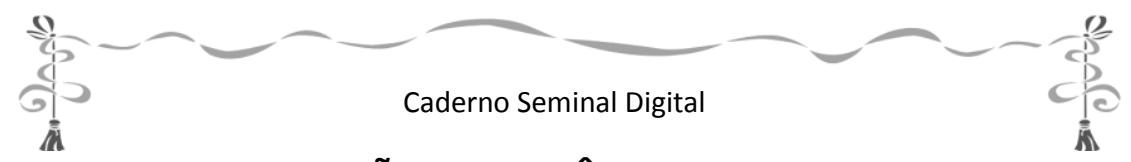

\title{
A EXACERBAÇÃO DA VIOLÊNCIA EM RICARDO III: DE SHAKESPEARE À MCKELLEN
}

Luiz R. Zanotti

Resumo: O ensaio analisa a adaptação fílmica do texto dramatúrgico Ricardo III de Shakespeare, elaborada pela dupla britânica Richard McKellen e Richard Loncraine. O roteiro realoca o rei-vilão para a Inglaterra dos anos 30, aproximando a imagem de Ricardo III à do ditador nazista Hitler. A adaptação reforça, sobremaneira, a tendência da elaboração de filmes violentos que, segundo o crítico James Lohelin (1997, s/n), apresenta-se como uma mescla de dois gêneros cinematográficos principais: filme sobre a tradição britânica e o filme americano sobre gangsters.

Palavras-chave: Adaptação fílmica, Fidelidade textual, Espaço da morte.

Abstract: The essay examines the film adaptation of the dramaturgical text Richard III of Shakespeare produced by the British duo Richard McKellen and Richard Loncraine. The script relocates the villain King of England in the 30s, approaching the image of Richard III at the Nazi dictator Hitler. The adaptation strengthens greatly the trend to produce violent movies that, according to critic James Lohelin (1997, s/n), presents as a mixture of two major film genres: film about the British tradition and American movie about gangsters.

* Luiz Zanotti é pós-doutorando em Literatura comparada na UFMG. Participa do grupo de Intermidialidade da UFMG, do GT de Intermidialidade da Anpoll e do Centro de estudos shakespearianos do Brasil.

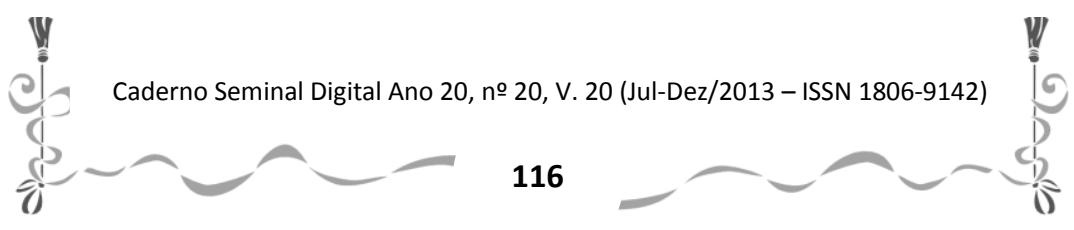


Keywords: Filmic adaptation, Textual fidelity, Space of death.

A película a ser analisada - Ricardo III (1992), de lan McKellen e Richard Loncraine - se inscreve numa das mais importantes de todas as práticas hipertextuais: a adaptação fílmica. Segundo Gérard Genette, as adaptações, de uma forma geral, possuem uma elevada importância histórica, seja pelo acabamento estético de certas obras que dela resultam, seja pela amplitude e variedade dos procedimentos nelas envolvidos (2006, p.27).

Os estudos de adaptação, para Linda Hutcheon, vão além da tradução semiótica de romances para filmes e, abarcam quase tudo: estórias de poemas, peças, pinturas, óperas, músicas e dança que são frequentemente adaptadas de uma mídia para outra (2006, p.XI). Simone Murray concorda com Hutcheon, no sentido de que os estudos de adaptação transcenderam o seu status inicial relegado às margens dos estudos literário/cinematográficos (2007, p.23). A adaptação no Século XXI recebeu as marcas de respeitabilidade acadêmica, o que pode ser percebido no extenso número de cursos de pós-graduação e de graduação que tratam do tema, bem como a atenção a ele dispensada pelas publicações de grandes editoras acadêmicas, como o jornal acadêmico Literature/Film Quarterly e o recém lançado Journal of Adaptation Studies.

Essa proliferação de hipertextos, uma das características da arte contemporânea, tem a sua base teórica

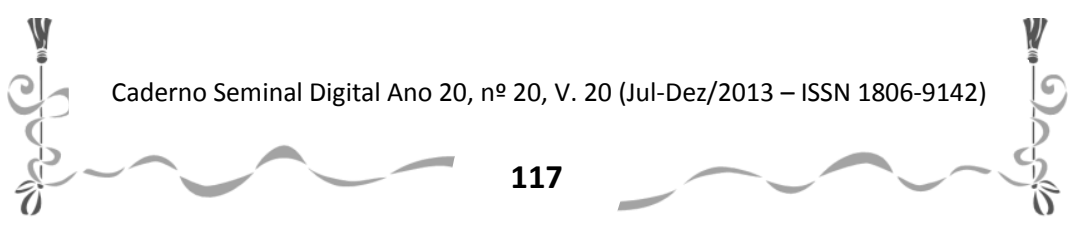


no enunciado de que toda obra de arte possui relações intertextuais não apenas, de uma forma direta, com outras obras de arte de estatuto igual ou comparável e, sim, de uma forma indireta, com todas as obras que influenciaram essas obras de igual estatuto: "De maneira mais direta: qualquer texto que tenha dormido com outro texto, dormiu também, necessariamente, com todos os outros textos com os quais este tenha dormido" (STAM, 2003, p.226).

Neste universo de adaptações, a obra de Shakespeare continua a inspirar cada nova geração pelo fato de possuir uma rara qualidade estética, por trabalhar uma visão de mundo ampliada e por sua incrível atualidade. Universalidade e atualidade que possibilitam a sua adaptação para as mais variadas mídias, reescrita através de novas formas e enfoques de produção desenvolvidos, pois, assim, como argumenta o pesquisador francês Jean Pierre Sarrazac: "Escrever no presente não é contentar-se em registrar as mudanças da nossa sociedade, é intervir na conversão das formas" (2002, p.34).

Nesse quadro contemporâneo de adaptações da obra de Shakespeare, Ricardo III de McKellen ${ }^{18}$ é um interessante caso de adaptação de um texto dramatúrgico de Shakespeare que, antes de alcançar a sua mídia final (o cinema), passa por

\footnotetext{
${ }^{18}$ Apesar da direção ser de Richard Loncraine, a realização como um todo parece ser objetivo de McKellen que além de atuar, é o roteirista junto com Loncraine.
}

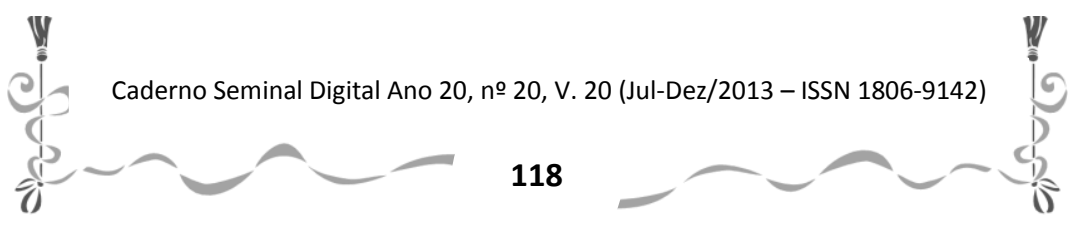


Caderno Seminal Digital

Â

uma primeira transformação ou experiência através da dramaturgia. Sir Ian McKellen, um dos maiores atores shakespearianos, afirma, na contracapa do livro que escreveu sobre essa sua experiência, que gostaria de passar todos os dias do resto de sua vida filmando Ricardo III. O resultado desse desejo é uma obra de tirar o fôlego, num filme estrelado por ele e dirigido por Richard Loncraine, que transforma a elogiada produção teatral de Ricardo III, encenada no Royal National Theatre, em duas horas de magia fílmica.

\section{RICARDO III: DE SHAKESPEARE À MCKELLEN}

O texto original de Ricardo III foi escrito entre 1592 e 1593 e é denominado $A$ tragédia de Ricardo III, dando clara ênfase ao processo de causa e efeito e à total responsabilidade de cada personagem por seus atos. Essa peça dá início às grandes tragédias que o dramaturgo iria realizar e faz parte dos dramas históricos em que Shakespeare fala do teatro e da representação do mundo. A obra foi elaborada a partir de um personagem que utiliza a dissimulação para fazer o mal. O autor, ao eleger um vilão para protagonista, acaba se defrontando com alguma perda do potencial trágico. Diferentemente de Hamlet e Macbeth que, segundo Raymond Willians, confrontam-se com as inescrutáveis forças morais da natureza e são destruídos por esta mesma natureza - e não pela sociedade -, a morte do vilão Ricardo III, no final da peça, adquire o significado de uma punição merecida, dada pela própria sociedade (2002, p.165).

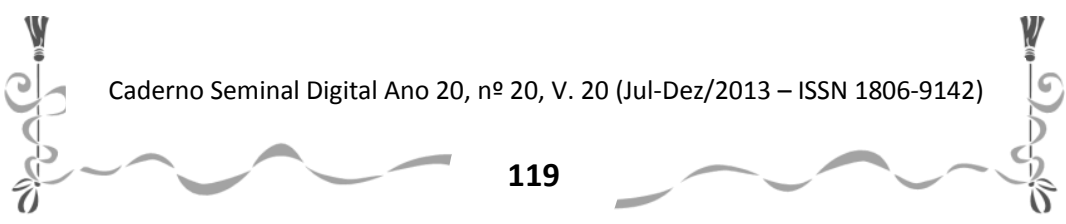


Caderno Seminal Digital

Â.

Para evitar a aproximação com o melodrama, Shakespeare constrói o seu protagonista como um personagem fascinante, por sua capacidade de dissimulação e ousadia, que acaba por arrebatar 0 espectador que, se não se envolve emocionalmente com o personagem, acaba por estabelecer uma ligação com ele, através da curiosidade em saber se Ricardo III irá ou não conseguir alcançar os seus propósitos, aclarados logo na primeira cena do primeiro ato, através de um monólogo dirigido diretamente à plateia.

No início do monólogo, Ricardo III conta seus planos em relação à coroa, estipulando o que ele quer e como pensa obter. A partir de então, no decorrer do espetáculo, Ricardo não se comporta como um vilão diante dos outros personagens, mas representa o papel de tímido e injustiçado, sempre através da uma admirável capacidade de dissimulação.

Ricardo III foi muitas vezes criticado por alguns julgarem que sua estrutura de confronto entre o bem e o mal fosse excessivamente formal. No entanto, Tom F. Driver afirma que, ao contrário de um simples melodrama, Shakespeare busca elaborar sua obra a partir de uma visão abrangente, universal e histórica, que possibilite o entendimento do restrito e do transitório, movendo-se numa atmosfera de memória, decisão e expectativa (1960, p.105). Harold C. Goddard chama a atenção para a jovialidade e genialidade de Shakespeare em sua impressionante

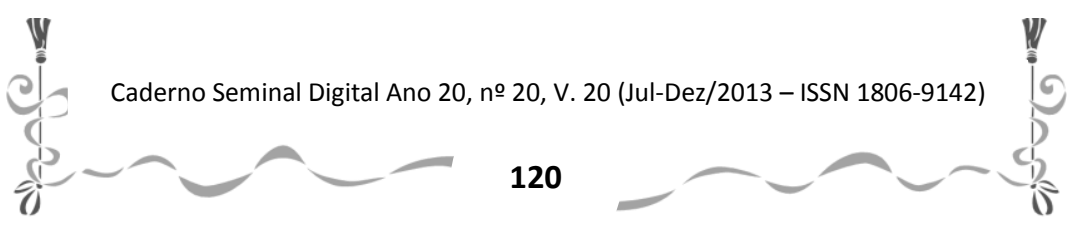


(1)

construção de Ricardo III, que o crítico considera como o clímax e conclusão dos oito dramas históricos escritos pelo dramaturgo (1951, p.35-40).

Além disso, Peter Saccio aponta para a mistura de estilos, com a linguagem que se apresenta como sublime e retórica nas falas de Richmond; como mundana e cômica, nos acontecimentos do segundo assassinato; e, entre esses dois extremos, no caprichoso, artificial e autodirigido discurso de Ricardo III (1997, p.157). Assim, a linguagem e a estrutura se unem para criar uma forma que expressa uma ação essencialmente temporal e histórica na concepção. Enfim, independentemente de sua análise crítica, a verdade é que Ricardo III, desde a sua estreia, tem sido extremamente popular em termos de público (Bloom. In: RAFFEL, 2008, p.196). Essa popularidade ocasionou inúmeras transposições de Ricardo III para outros meios, tais como o teatro, o cinema, a ópera, o musical e o balé.

A adaptação de McKellen trabalha de forma a relativizar $o$ imenso mistério envolvido com relação à personalidade Ricardo III e as circunstâncias em que assumiu o trono. É importante notar que, com a derrota de Ricardo III na batalha de Bosworth, Henrique VII, ao assumir o trono, provavelmente fez com que os historiadores de sua corte retratassem o rei derrotado como um tirano que merecia ser deposto pelo representante da família Tudor.

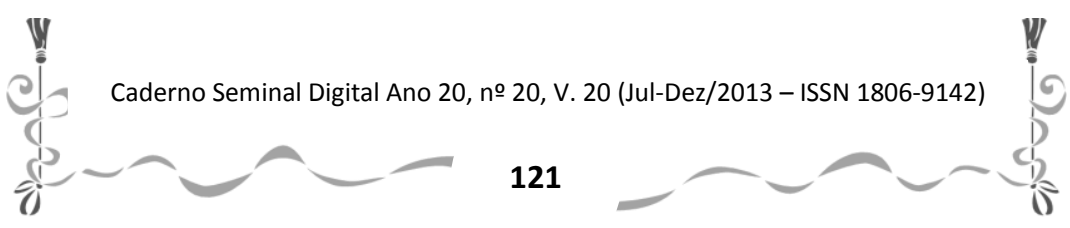


Dessa forma, McKellen vai seguir o estereótipo do personagem Ricardo III como um homem corcunda, com a perna esquerda muito maior que a direita, e caolho; detalhes que, ao serem apresentados por Sir Tomas Moore em seu livro, História de Ricardo III, transformou essa imagem de vilão numa "verdade histórica". Ian McKellen traz este Ricardo III para os anos 30, oferecendo a problematização de como pode ser feita uma adaptação do texto de Shakespeare, com as diferenças entre a performance teatral e as possibilidades técnicas do cinema (enquadramento, edição etc.), e como a imagem de uma visão suplementar pode substituir o texto shakespeariano.

Assim, Ricardo III foi, em grande parte, produzido num estilo que Jack Jorgens (1991) chama de modo realista, o que, em sua tipologia, significa filmes "teatrais" que simplesmente transferem performances teatrais para a tela e versões filmadas que re-imaginam substancialmente a peça em termos de estética e recursos na nova mídia. O filme realista shakespeariano é caracterizado por um tipo de atuação meio naturalista, cinematográfica e editada, que é usada na maioria dos filmes de Hollywood.

Os personagens são representados como "pessoas reais", com maquiagem e figurino plausíveis, e os filmes relatam a narrativa fácil de ser aceita sem chamar a atenção para a mídia. Esses filmes não são, obviamente, realistas no sentido de imitar nenhuma experiência atual de mundo; mas

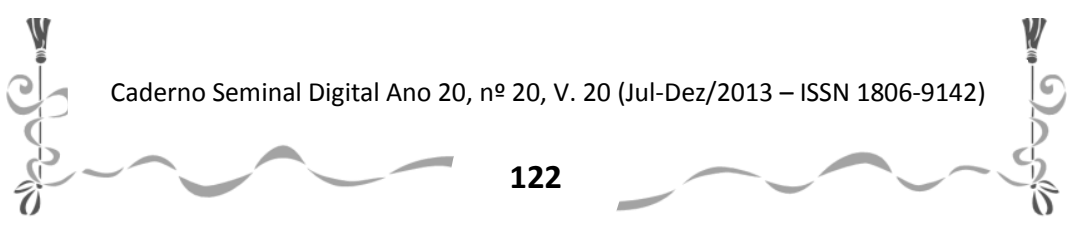


Caderno Seminal Digital

î.

essas convenções cinematográficas, tal como a continuidade de edição e trilhas sonoras, são tão universais que elas, ao menos, são percebidas pela maioria dos espectadores.

A nova onda de filmes shakespearianos, buscando por um pedaço do grande público de Hollywood, se apoia nas condições hollywoodianas, fazendo com que o Otelo de Parker seja anunciado pela Columbia Pictures como um suspense-erótico, o que o torna tão acessível como Atração Fatal. Ainda, enquanto os outros novos filmes de Shakespeare empregam essas convenções que estão no centro das atenções, num caminho inconsciente e de fácil aceitação, Ricardo III abraça e explora essas convenções para fazer um surpreendente e imaginativo filme shakespeariano que pode ser verificado em cada polegada do filme. (LOEHLIN, 1997, p. 75.)

Ricardo III tem como um de seus hipotextos a produção teatral homônima, dirigida por Richard Eyre, com Ian McKellen como Ricardo III, o que despertou o desejo de Kellen para uma versão fílmica da performance, uma vez que uma produção teatral só sobrevive na memória daqueles que estiveram pessoalmente ou no palco, ou na plateia, ou na produção. Dessa forma, uma primeira tentativa de registro da obra se deu pela sua própria gravação. No entanto,

O caminho mais óbvio de se preservar uma performance ao vivo é a menos satisfatória, Ricardo III foi gravado ao vivo através de três filmadoras, sendo que essas filmagens são apresentadas simultaneamente no museu Convent Garden, o que possibilita que 0 visitante edite, assim como a

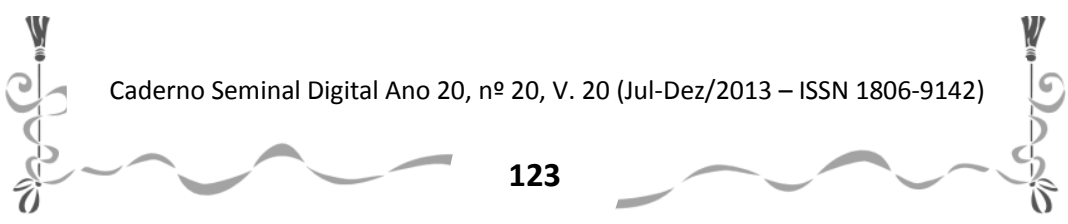




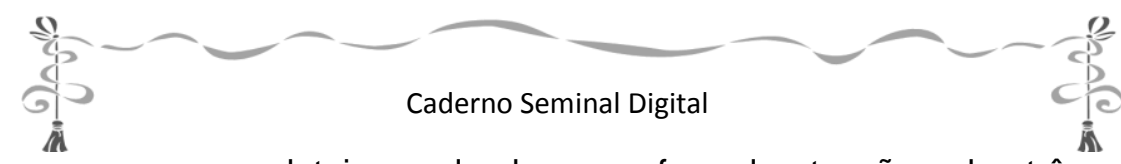

plateia, mudando o seu foco de atenção pelas três imagens. Se esse sistema tem alguma serventia em termos acadêmicos, ele não captura muito do impacto da cena original. [...] Hamlet, que foi gravada para a televisão, parece mais um comentário gravado acontecendo através da performance do que uma peça teatral, o que pode só interessar aos estudantes do texto, mas não para quem quer encontrar Hamlet e não lan McKellen. (MCKELLEN, 1996, p.7)

McKellen pretendia fazer uma versão fílmica da peça, tendo, no entanto, o conhecimento de que muitos atores que protagonizaram alguma adaptação de Ricardo III de Shakespeare, antes dele, não haviam conseguido êxito de público, citando, como exemplo disso, Al Pacino na adaptação Looking for Richard, mas, lembrando, como grande exceção, a transposição efetuada por Lawrence Oliver do palco para a tela de seu Ricardo III (MCKELLEN, 1996, p.7).

Frente a esse desafio, McKellen buscou a colaboração de Loncraine, surpreendentemente, um diretor de anúncios de televisão e filmes comerciais sem possuir nenhuma experiência na dramaturgia shakespeariana ou mesmo teatral. Contudo, foi a partir da produção teatral de Richard Eyre que o filme assume a sua mais importante escolha interpretativa: a realocação da ação para a Inglaterra dos anos 30 e a apresentação de Ricardo III como um ditador fascista. Embora o filme explore o paralelo histórico mais pontualmente do que a produção teatral faz, e a performance de McKellen no palco,

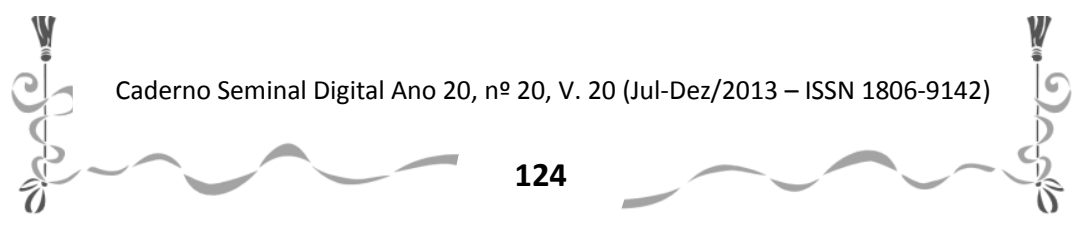


Caderno Seminal Digital

por se apresentar de uma maneira mais formal e elaborada, resulte em algo falso ou artificial, sem dúvida, a sua performance no filme é menos óbvia e mais efetiva (LOEHLIN, 1997, p. 67).

Numa abordagem realista, Loncraine explora uma série de poderosas imagens, sendo, a mais óbvia, o momento em que no Ricardo III é aclamado rei pelos cidadãos. A mídia cinematográfica permite a Loncraine criar uma convincente realidade dos anos 30, estabelecendo uma incrível historicidade através de uma superabundância de detalhes visuais, tais como as limusines Bentley, os cigarros Abdula, os revólveres Sten e os edifícios construídos num estilo arquitetônico quase fascista. Ricardo III, em sua versão teatral, não conseguia o mesmo efeito, uma vez que a década de trinta era representada principalmente pelo vestuário, o que resultava em algo que parecia ter sido estabelecido arbitrariamente. De uma maneira geral, para o crítico James Lohelin, como já observado, o filme pode ser definido como a mescla de dois gêneros cinematográficos principais: filme sobre a tradição britânica e o filme americano sobre gangsters (1997, s/n).

\section{UMA TRAIÇÃO AO TEXTO SHAKESPEARIANO?}

Para a pesquisadora Thais Flores Diniz, a maioria das adaptações (fílmicas) tem sua origem em uma narrativa, e o que se entende normalmente por adaptação é, pois, a versão cinematográfica de uma obra de ficção (1999, p.41). Essa é a

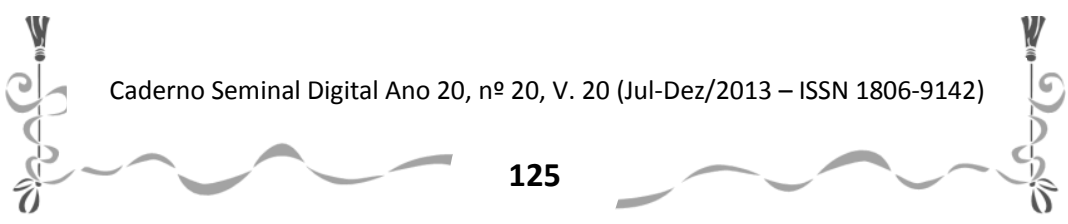


Caderno Seminal Digital

a

razão de, ao se abordar o tema da adaptação, pensar-se prioritariamente em uma fonte literária. Assim, o processo de adaptação vem sendo visto como unidirecional - caminhando sempre do literário para o fílmico - e priorizando o primeiro em detrimento do segundo. Em consequência, o estudo da adaptação tendeu a se concentrar na comparação entre os dois tipos de textos e na medida do sucesso alcançado pela transferência de um para o outro. Em síntese, a preocupação dos críticos vem sendo verificar a fidelidade do filme à obra de ficção, isto é, se o filme consegue captar todos os elementos da narrativa, enredo, personagem etc.

Dentro deste panorama, muitas adaptações da obra de Shakespeare ainda continuam a ser analisadas e julgadas a partir da proximidade ou afastamento do texto, num processo onde a fidelidade à obra ocupa um lugar privilegiado. Entretanto, o pesquisador Robert Stam discorda desta visão moralista das adaptações de romances ao cinema, pois, para ele, a linguagem convencional da crítica tem sido profundamente moralista, rica em termos que sugerem um desserviço à literatura, tais como "infidelidade", que carrega insinuações de pudor vitoriano; "traição", que evoca perfídia ética; ou "deformação", que sugere aversão estética e monstruosidade; mas poderiam, muito bem, serem substituídas por expressões positivas que não ignorassem o que foi "ganho" (2006, p.20).

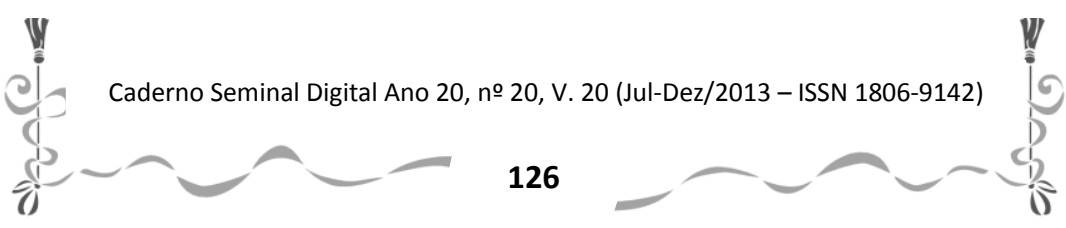


Caderno Seminal Digital

Neste sentido, podemos afirmar que a obra a ser analisada não constitui nenhuma perda com relação à obra original, pois ela pertence a uma rede infinita de hipertextos que são criados através das diferentes mídias e culturas e não necessariamente se constituem como tal. A pesquisadora Thais Flores N. Diniz, em seu artigo "Shakespeare Transcultural", afirma que:

O fato de Shakespeare estar sendo constantemente traduzido em várias línguas e culturas, através de vários meios de comunicação, dentre eles o cinema, traz consigo a vantagem de que ao se verificar que o tratamento dado à ordem foi diferente em cada filme, podemos concluir que esse elemento puramente cultural mostrou-se crucial para a manifestação criativa dos vários tradutores. (2013)

Diante destas considerações críticas, pode-se dizer que Ricardo III de McKellen faz parte de uma complexa e infinitamente grande rede de trabalhos artísticos (hipertextos) que dialogam entre si em diferentes mídias, linguagens e paisagens. Dentro desta perspectiva trabalharemos com a ideia que um texto sofre uma transformação quando de uma adaptação fílmica, ou seja, o resultado é sempre uma nova leitura que proporciona um novo texto, com diversos graus de aproximação ou distanciamento em relação ao texto-fonte, sendo que:

A operação de passagem da linguagem de um meio para outro implica em consciência tradutora capaz de

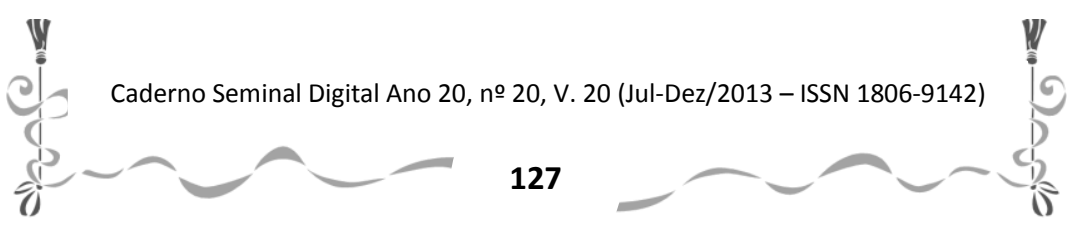




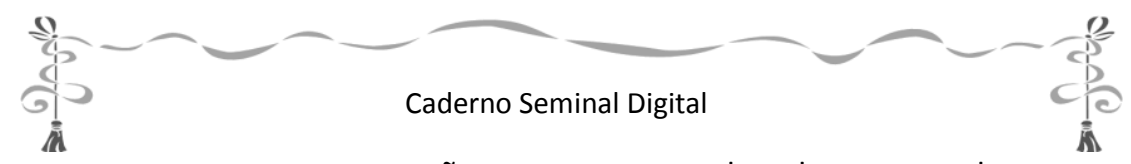

perscrutar não apenas os meandros da natureza do novo suporte, seu potencial e limites, mas, a partir disso, dar o salto qualitativo, isto é, passar da mera reprodução para a produção. (PLAZA, 2003, p.109)

Mas, apesar de o conceito de adaptação mais amplamente difundido ser o que se refere a filmes cujas histórias foram narradas por obras literárias, esse conceito vem se ampliando para abranger outros textos, não apenas os literários. Para Patrice Pavis, o conceito de adaptação pode ter vários sentidos, entre eles o da transposição ou transformação de uma obra de um gênero em outro ou de um romance em uma peça, por exemplo (1999, p.10).

Esta relação entre textos se torna ainda mais abrangente se usarmos o conceito de texto definido por Barthes:

[...] um campo metodológico de energia, uma produção em processo, que absorve o leitor e o escritor juntos; [...] não uma sequência de palavras que expressa um único sentido teológico mas um espaço multidimensional no qual uma variedade de escritas, ou nenhuma delas original, se funde e se contrapõe. (In: DINIZ, 1999, p.43)

$\mathrm{Na}$ mesma direção, Clüver menciona que todas as artes, a música, pintura, escultura, fotografia, desenho, cinema, literatura etc., podem ser pensadas em termos de textos passíveis de serem lidos (2001, p.351). Porém, Diniz lembra que o que a hipertextualidade enfatiza não são as similaridades entre os textos, mas as operações

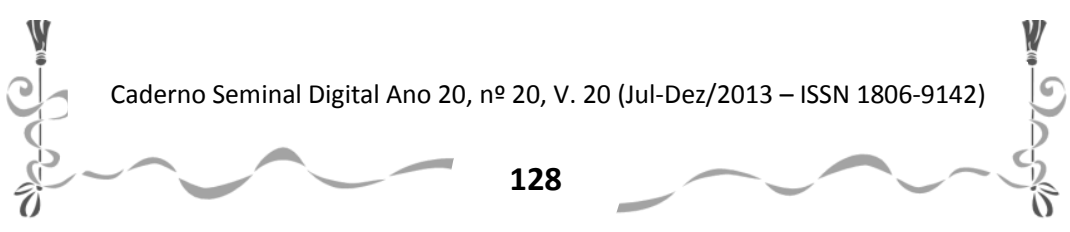


Caderno Seminal Digital

î.

transformadoras realizadas nos hipotextos, sendo que algumas delas desvalorizam e trivializam os textos préexistentes, outras reescrevem-nos em outro estilo; outras reelaboram certos hipotextos cuja produção é, ao mesmo tempo, admirada e menosprezada (1999, p.44-45). Outras, ainda, modernizam obras anteriores, acentuando certas características do original. Todavia, em muitos casos, o que se transpõe não é uma única obra, mas todo um gênero. Um conceito abrangente de hipertextualidade inclui, portanto, os remakes, as sequels, as versões revisadas de westerns, os pastiches genéricos, as reelaborações e as paródias.

Além disso, a adaptação não se limita à comparação dos aspectos semióticos, pois este fenômeno pode ser visto como uma manifestação de um processo cultural em constante mutação. O conceito de adaptação deve ser ampliado como sendo um processo dialógico, complexo e multidirecional, que inclui os conceitos de intertextualidade, tradução intersemiótica, tradução cultural e hipertextualidade.

\section{A EXACERBAÇÃO DA VIOLÊNCIA}

A nova leitura de Ricardo III, oferecida por McKellen, logo nos primeiros momentos, apresenta uma das características do seu filme, qual seja, a exacerbação da violência em relação a outras adaptações fílmicas como a montagem estadunidense de 1912, dirigida por James Keane e estrelada pelo legendário ator teatral Frederick Warde, ou a

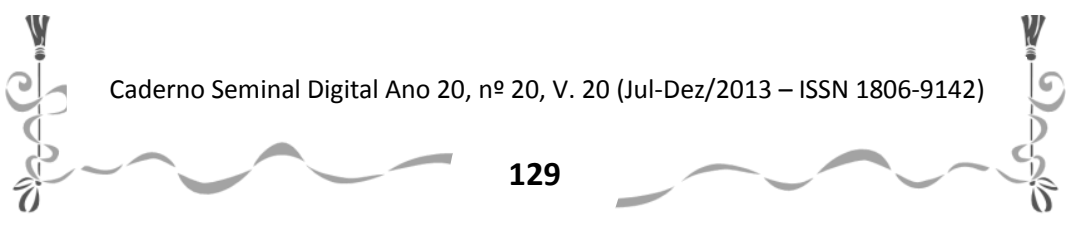


Caderno Seminal Digital

î

montagem efetuada por Lawrence Oliver, logo após o final da Segunda Guerra Mundial. O primeiro registro cinematográfico mostra um tanque adentrando violentamente a sala de estar onde o príncipe Edward (dinastia Tudor) está jantando:

Como a aparição do tanque não poderia ser regravada ou repetida, quatro câmeras filmaram a sua única solitária entrada, que é seguida pelo "off" de uma respiração ritmada através de uma mascara de gás. Dessa forma, num primeiro momento o rosto de Ricardo III está mascarado, uma forma apropriada para mostrar os seus sentimentos com relação ao mundo. (MCKELLEN, 1996, p.46)

Loncraine, desde o início, vai buscar a violência, através do realismo cinematográfico, na imagem efetiva de um tanque de guerra, em contrapartida à concretude cênica do teatro, que é efetuada através de um personagem que existe como imaginário na atividade mental do espectador, pois, no palco, só encontramos homens, madeira, pano, gestos, palavras reais, colocados como "imagens" que devem ser consideradas analogicamente como metáforas. A adaptação fílmica traz, em sua origem, uma diferença de estilos entre ela e a versão teatral, pois, para Denis Guénoun, o cinema realiza o imaginário em imagens efetivas:

Não basta apresentar o análogo de um objeto para que este substituto tenha direito, em sentido próprio, à denominação de imagem. [...] As imagens do cinematógrafo tornam-se imagens efetivas [...], relegando todas as outras espécies de imagem à situação

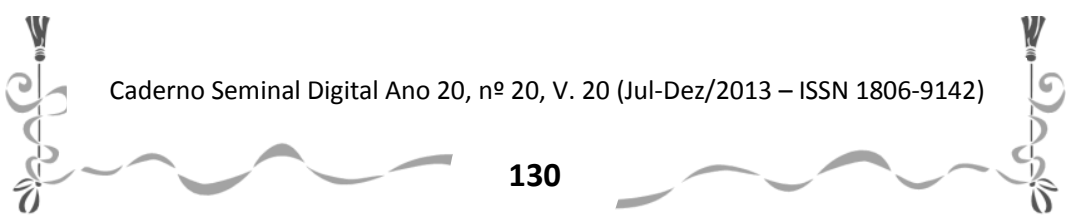




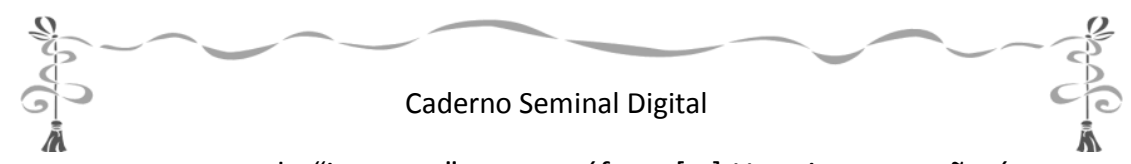

de "imagens" por metáfora. [...] Uma imagem não é uma ficção. Imago não é fictio. Nem uma alegoria, nem um símbolo, nem um signo, nem um substituto figurado da coisa. (2004, p.102)

Essa constatação acarreta duas consequências: qualquer coisa passa diretamente do corpo para a imagem sem que haja qualquer subjetividade formadora, como é o caso de uma pintura, onde existe a transferência de medidas, de linhas ou de volumes, por contato, por contiguidade do corpo com a forma depositada; e a imagem do "morto", uma imagem que atesta o passado, dá testemunho do ausente, uma vez que este ausente esteve presente no lugar atual e determinado pela sua ausência. Conforme Guénoun,

[...] a fotografia atesta sem refutação possível a presença do que esteve ali e se ausentou. A fotografia dá a ver a presença - por default - do que está morto, ou, ao menos, do instante que se foi irremediavelmente. [...] Há dupla posição conjunta: de realidade e de passado. [...] 0 que ilustra a observação abissal de Barthes a respeito da foto, mais que centenária, de um condenado a morte antes da execução: ele está morto, e ele vai morrer. (2004, p.105)

Dessa forma, o cinema recebe, pela fotografia, sua impressão do real, e, assim, partilha de uma conaturalidade com o referente. Tudo se passa como se o cinema tivesse libertado o imaginário do espaço mental onde estava confinado, para lhe dar estatuto de ente objetivo. O cinema é o imaginário realizado, confiscando o imaginário de um teatro

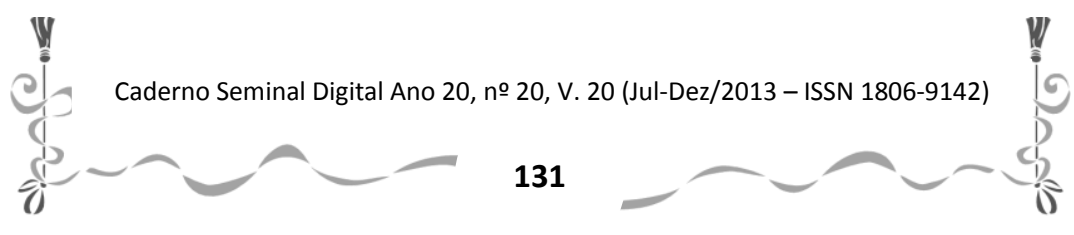


Caderno Seminal Digital

î.

que estava com a cena cindida em duas: (i) existentes práticos (atores, cenários, adereços, luzes, etc.) e existentes imaginários (personagens, histórias etc.). O cinema realizou as produções imaginárias da cena, dando-lhes existência concreta, assegurando a sua independência, a libertação em relação à cena e os seus protocolos. (GUÉNOUN, 2004, p.107110)

Ainda na sequência do início, a exacerbação da violência acontece na figura de um soldado, identificado depois como Ricardo III, que sai do tanque e assassina o velho rei indefeso que se encontrava rezando sobre a sua cama:

Através das chamas e da fumaça acre, Ricardo, o duque de Gloucester, em seu uniforme de batalha e com uma máscara de gás que encobre o seu rosto, sai por cima do tanque de guerra, liderando alguns comandados.

Dois dos ajudantes de ordem do príncipe Edward são rapidamente alvejados pelos invasores. Ricardo checa se o príncipe está mesmo morto e então aparece entrando através de uma porta dupla. Ele as deixa abertas. Tremendo, rezando uma oração, o velho rei. Ele procura pela figura apagada no corredor. Uma saraivada de balas sai de sua metralhadora Stein e o corpo do velho rei cai atrás da cama com o impacto das balas. (MCKELLEN, 1996, p.47)

Na continuidade, Richard tira a sua máscara de gás revelando que o personagem foi desenvolvido iconicamente, ligado a Hitler pelo seu corte de cabelo e forma do seu bigode,

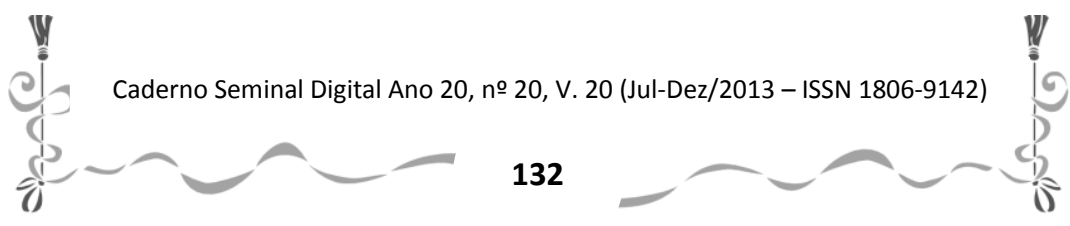


Caderno Seminal Digital

mas, no entanto, o seu uniforme o identifica com um oficial de alta patente, como Sir Oswald Mosley, o carismático líder da União dos fascistas da Grã-Bretanha.

A violência vai continuar por toda a película, na maioria das vezes apresentando com detalhes cada um dos assassinatos encomendados por Ricardo III e possibilitando a problematização desta violência exacerbada a partir do conceito do "espaço da morte", construído pelo antropólogo americano Michael Taussig. O "espaço da morte" deve ser interpretado como uma importante criação do significado e da consciência em sociedades onde a cultura do terror floresce.

Para Taussig, a cultura do terror é nutrida na trama formada entre o silêncio e do mito, a ênfase do lado misterioso está no rumor finamente tecido em teias de realismo mágico (1993, p.19). Ricardo III cria o seu "espaço da morte" como forma de impingir um temor mental agudo e, em grande parte, da agonia física da morte, numa íntima dependência mútua entre a verdade e a ilusão e entre o mito e a realidade; tudo isto relacionado com o metabolismo do poder, fazendo com que ele assuma o trono da Inglaterra sem grande resistência pelo desaparecimento dos príncipes herdeiros.

\section{CONCLUSÃO}

Apesar da exacerbação da violência que aproxima o Ricardo III "nazista" do gênero fílmico de guerra do cinema

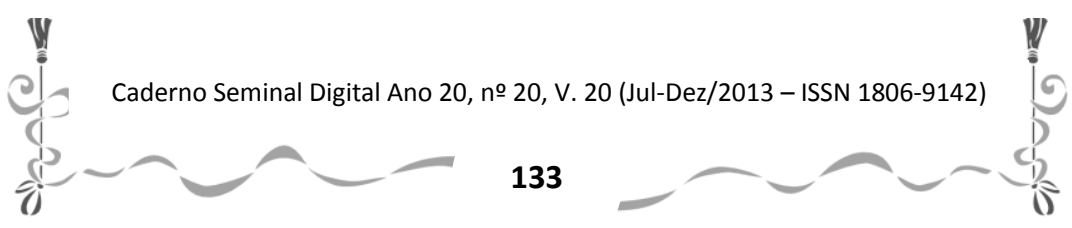


Caderno Seminal Digital

Ầ

americano, McKellen consegue deixar clara a relação entre violência e poder no caminho de Ricardo III até o trono e acaba por tornar a obra de Shakespeare mais acessível para o público em geral do cinema, que sai com a ilusão da alma lavada, pois, afinal, o vilão se suicida, num castigo exercido por uma força divina, sem nem mesmo ser preciso que o mocinho suje as suas mãos.

\section{REFERÊNCIAS BIBLIOGRÁFICAS:}

CLÜVER, Claus. Estudos Interartes: introdução crítica. Trad. do inglês de Yung Jung Im e Claus Clüver. In: BUESCU, Helena Carvalhão;

DUARTE, João Ferreira; Gusmão, Manuel (orgs.). Floresta encantada: novos caminhos da literatura comparada. Lisboa: Dom Quixote, 2001. pp.333-362.

DINIZ, Thaïs F.N. Literatura e Cinema: da semiótica à tradução cultural. Ouro Preto: Editora UFOP, 1999.

.Shakespeare Transcultural. Disponível em:

http://www.thais-

flores.pro.br/artigos/PDF/Shakespeare\%20transcultural.pdf.

Acessado em 12. jan. 2013.

DRIVER, Tom F. The Sense of History in Greek and Shakespearean Drama. New York: Columbia, 1960.

GENETTE, Gérard. Palimpsestos a literatura de segunda mão. Trad. de Luciene Guimarães e Maria Antônia Ramos Coutinho. Belo Horizonte: Faculdade de Letras, 2006.

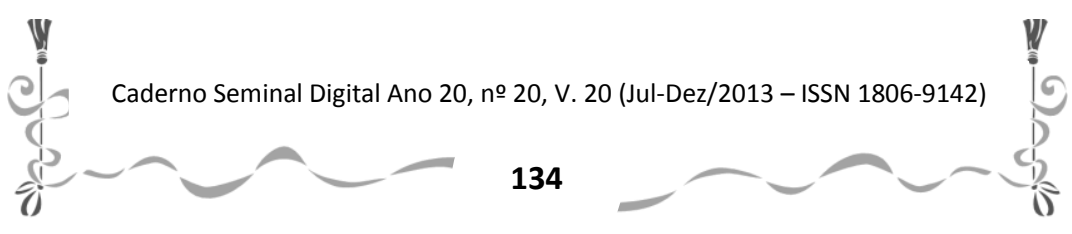


Caderno Seminal Digital

î.

GODDARD, Harold C. The meaning of Shakespeare. 2v. Chicago: University of Chicago Press, 2006.

HUTCHEON, Linda. A Theory of Adaptation. London: Routledge, 2006.

GUÉNOUN, Denis. O Teatro é Necessário? Trad. Fátima Saadi. São Paulo: Perspectiva, 2004.

JORGENS, Jack. Shakespeare on film. Lahan: Indiana Press, 1991.

LOEHLIN, James N. Top of the World, Ma: Richard III and Cinematic Convention. In: Shakespeare, the Movie: Popularizing the Plays on Film, TV, and Video. London: Routledge, 1967. pp.67-79.

LONCRAINE, Richard. Richard III. Londres: Bayly/Paré.Mc, 1992.

PAVIS, Patrice. Dicionário de teatro. Trad. de J. Guinburg e Maria Lúcia Pereira. São Paulo: Perspectiva, 1999.

MCKELLEN. Richard III. London: Transworld, 1996.

PLAZA, Júlio. Tradução Intersemiótica. São Paulo: Perspectiva, 2003.

RAFFEL, Burton (org). Richard III. New Haven: Yale University, 2008.

SARRAZAC, Jean-Pierre. O futuro do drama: Escritas dramáticas contemporâneas. Trad. Alexandra Moreira da Silva. Porto: Campo das Letras, 2002.

SHAKESPEARE, William. Ricardo III; Henrique V. Trad. Bárbara Heliodora. Rio de Janeiro, 1993.

STAM, Robert. Introdução à Teoria do Cinema. Trad. Fernando Mascarello. Campinas: Papirus, 2003.

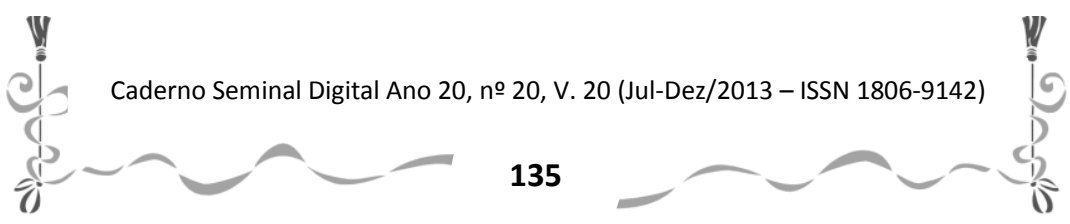


Caderno Seminal Digital

- Teoria e prática da adaptação:da fidelidade à

intertextualidade In: I/ha do desterro. n.51. Florianópolis, jul./dez, 2006. pp.19-53

WILLIAMS, Raymond. A tragédia moderna. São Paulo: Cosacnaify, 2002.

TAUSSIG, Michael. Xamanismo, colonialismo e o homem selvagem. Trad. Carlos Eugênio Marcondes de Moura. São Paulo: Paz e Terra, 1993. 